\title{
Land Use Drivers of Population Dynamics in Tasks of Security Management and Risk Assessment
}

\author{
Ivan Kopachevsky ${ }^{1}$, Yuriy V. Kostyuchenko ${ }^{1 *}$, Otto Stoyka ${ }^{2}$ \\ ${ }^{1}$ Scientific Centre for Aerospace Research of the Earth, National Academy of Sciences of Ukraine \\ 55-b, O. Honchar Street, Kiev, 01601, Ukraine, ${ }^{1 *}$ yuriy.v.kostyuchenko@ gmail.com \\ ${ }^{2}$ Kiev Municipal Health Center, Kiev, 103, Kyrylivska Street, Kiev, Ukraine, ${ }^{2}$ otto.stoyka@ gmail.com \\ "Corresponding author
}

(Received February 26, 2016; Accepted March 1, 2016)

\begin{abstract}
Approach to population data disaggregation in tasks of risk assessment is presented in this paper. The approach is based on analysis of land cover distribution separately in rural and urban areas. Model to analyze a population distribution on regular grid in a study area is proposed. Formal algorithms to estimate disaster losses distributions depending on population distribution, agroecological, socio-economic, and socio-ecological parameters are proposed. Concluding on population vulnerability and losses distribution in depending of land-use factors are proposed.
\end{abstract}

Keywords- Population density, Disaster losses, Rural and urban areas, Agroecology, Infrastructure accessibility, Resources availability.

\section{Introduction}

Socio-Economic Drivers of Disaster Losses Distribution

Human issues are one of the main components of modern security concept (Lutz and Samir, 2011; Kostyuchenko and Movchan, 2015). Modern understanding of complex security and complex risk management requires analysis of all natural and social phenomena, the involvement of all available data, the construction of advanced analytical tools, and the transformation of our understanding about vulnerability, perception of risk and security (Kostyuchenko et al., 2015). In some sense the risk management becomes from subject of engineering protection to a subject area of social construction (Nelkin, 1989; Spink et al., 2007). So, social data should plays here a significant role.

In many tasks, first of all, in tasks of security management and risk assessment, a population density data is a very important component. Usual statistical data propose aggregated information on selected period by regions or megacities/urbanized areas. But for correct risk and vulnerability analysis we need population density distribution on regular grid. Also it is important to analyze a local heterogeneity of regional parameters influencing to population density and dynamics. In particular, distribution of disaster losses depends on population density, as it demonstrated (Kostyuchenko, 2016).

In general case the linearised form of natural disaster losses distribution regression might be proposed as follows (Kostyuchenko, 2016; Kellenberg and Mobarak, 2008):

$$
\begin{aligned}
& \ln \left(p_{i, t}(x, y)\right)_{r}=a_{1} P_{i, t}+a_{2} F_{i, t}^{d}++a_{3} \ln I_{i, t}+a_{4}\left(\ln I_{i, t}\right)^{2}+a_{5} P_{i, t}^{U R}+ \\
& +a_{6}\left(\ln I_{i, t} P_{i, t}^{U R}\right)+\xi_{i, t}^{(x, y)}
\end{aligned}
$$


International Journal of Mathematical, Engineering and Management Sciences

Vol. 1, No. 1, 18-25, 2016

https://dx.doi.org/10.33889/IJMEMS.2016.1.1-002

Here, $a_{n}$ - regression empirical coefficients; $F^{d}{ }_{i, t}$ - frequency of disasters on the site $(x, y) ; I_{i, t}-$ per capita income of people group $i$ in time $t$ on the site $(x, y) ; P_{i, t}$-population in time $t$ on the site $(x, y) ; P^{U R}{ }_{i, t}$ - urban population/social density in time $t$ on the site $(x, y)$; and $\xi$ - uncertainty coefficient.

Proposed equation (1), which describes natural disasters losses, requires detailed data on used parameter such as distribution of population density, or income.

This regression has been calculated from disaster data (National report, 2010), which were analysed using modified Kernel-based nonlinear Principal Component Analysis (KPCA) algorithm (Kostyuchenko, 2015).

Therefore, there is a task on development of algorithm to estimate on regular grid a population density on the area studied. This assessment should be based on local heterogeneities of natural and man-made parameters. So, this is a data disaggregation task.

\section{Problem-Oriented Stochastic Model of Population Distribution}

Since usually we have not enough accurate data on population distribution and dynamics, and population statistics is an object of statistical estimations, we can evaluate a value $P_{i, t}-$ population in time $t$ on the site $(x, y)$ as the stochastic value. For it we can use data on land cover distribution as a synthetic data on number of natural and social factors acting during a long period across the area studied. First of all the urban and rural areas should be analyzed separately due to the difference of factors affecting to population distribution and dynamics.

Urban areas are cities and urban-type localities, officially designated as such, usually according to the criteria of number of inhabitants and predominance of agricultural, or number of nonagricultural workers and their families. In our context we will recognize as urban areas the agglomerations of about 2000 or more inhabitants, generally having population densities of more than 500-1000 persons per square kilometer or more. Three types of urban areas could be recognized: megacities of 1 million or more inhabitants; urbanized areas of 50000 or more inhabitants and less than 1 million inhabitants, and urban clusters of at least 2000 and less than 50000 inhabitants. Besides, two types of small towns (up to 6000 inhabitants) can be determined: with population density 400-700 persons per square kilometer, and with population density 7001500 persons. Second type of small towns is more industrialized.

Rural area is a sparsely populated area outside of the limits of a city or town or a designated commercial, industrial, or residential center. Rural areas are characterized by farms, vegetation, and open spaces. Primary industry in most rural areas is agriculture.

If site $(x, y)$ is the part of mixed area with urbanized and rural districts, population in the site investigated could be presented as (Tian et al., 2005; Kostyuchenko, 2016):

$P_{i, t}{ }^{(x, y)}=\frac{\mu_{i}^{R U R} P_{i}^{R U R}}{\sum_{x, y} \mu_{(x, y)}^{R U R}}+\frac{\mu_{i}^{U R} P_{i}^{U R}}{\sum_{x, y} \mu_{(x, y)}^{U R}}$ 
International Journal of Mathematical, Engineering and Management Sciences

Vol. 1, No. 1, 18-25, 2016

https://dx.doi.org/10.33889/IJMEMS.2016.1.1-002

where $P_{i}^{R U R}$ - rural population, $P_{i}^{U R}$ - urban population, $\mu^{R U R}$ - rural probability density coefficient, $\mu^{U R}$ - urban probability density coefficient for the certain site.

\section{Rural Areas Population Distribution Drivers: Natural Productivity, Agroecology, Resources Availability, Markets and Infrastructure Accessibility}

Rural population will be determined by the rural population probability density coefficient $\mu_{i}^{R U R}$, which could be defined as:

$\mu_{i(x, y)}^{R U R}=\sum_{n,(x, y)} u_{n,(x, y)} S_{(x, y)}$

where $u_{n,(x, y)}$ - agroecological zoning coefficient for land-use type $n$ in site $(x, y) ; S_{(x, y)}$ - square of land-use type in site $(x, y)$.

Agroecological zoning coefficient include number of parameters (Fischer et al., 2002):

$u_{n} \rightarrow h_{n}\left(A_{n} ; \delta\right) \bar{y}_{n}\left(x_{n}\right)$

where $h_{n}$ - land index, calculated for each region taking into account pollutions and soil degradation, $A_{n}$ - type of land-use, $\delta$ - scaling parameter, $\bar{y}_{n}$ - maximum attainable yield, depends of $x_{n}$ - agro-ecological condition, which includes parameters of terrain, soil, water: moisture and precipitation, climate and temperature.

Maximum attainable yield may be assessed as the functional of annual statistical yield maximum:

$\bar{y}_{n} \rightarrow y \cdot(1-u) \cdot f(k) \cdot S(T, W, R)+\Delta$

where $u$ - crop degradation index; $f(k)$ - function of crop density; $S(T, W, R)$ - productivity functional depends of distributions of temperature, water load and radiation; $\Delta$ - uncertainty coefficient (Gommes et al., 1981).

Rural population vulnerability determines by natural conditions, quality of lands, effectiveness of land use, intensity of pollutions, crop productivity variations during the period of crop rotation (Kostyuchenko et al., 2013; Movchan et al., 2014) and market conjuncture.

Additionally, there is a local parameter, which connects population and income distribution through variations of consumer prices of agricultural production. In the framework of general stochastic socio-economic regional model (Fischer, 1996) a production function of "aggregate farmer" should include output index with available provincial prices $p_{r c}$ for yield $y_{r c}$, the national prices $p_{c}$, including weighting coefficient $w_{l}$ (Albersen et al., 2002): 
International Journal of Mathematical, Engineering and Management Sciences

Vol. 1, No. 1, 18-25, 2016

https://dx.doi.org/10.33889/IJMEMS.2016.1.1-002

$p_{r}^{i}=w_{l} \frac{\sum_{c} p_{r c} y_{r c}}{\sum_{c} p_{c} y_{r c}}$

where $w_{l}$ determined in terms of density of urban population $P_{i}^{U R}$, coefficient of infrastructure availability (usually reflecting the road quality) $\beta$, and distance $l$ ' between the given county and all other cities and county towns as:

$w_{l}=\sum_{l^{\prime}} \frac{P_{l^{\prime}}^{U R}}{\exp \left(0.01 \cdot \beta_{l} \cdot d i s \tan c e_{l, l^{\prime}}\right)}$

This type of stochastic approach with necessary constrains and measurable variables described and discussed in (Movchan et al., 2014). The methods to control current productivity $y_{r c}$ as well as its variations are also proposed (Kostyuchenko et al., 2013).

Therefore, a rural population distribution (and its vulnerability in tasks of risk assessment) will depends also on distribution of urban population, in particular, on distance to city centres $l$, and on national distribution of crops output.

\section{Urban Areas Population Distribution Drivers: Urban Planning, Infrastructure Quality, Social Security}

Population on urbanized areas is distributed by other low, and it vulnerability should be described with other relations.

General model of urban population density $p_{n}$ in region $n$ can be presented, according to (Clark, 1951; Chen, 2008) as:

$p_{n}(r) \propto \sum_{n(x, y)} p_{n(o)} \cdot \exp \left(-\frac{r_{n}}{r_{n(o)}}\right)^{\sigma}$

where $p_{n(0)}$ is the population density in the urban centre, $r_{n}$ - distance of area $n$ with localization $(x, y)$ to centre of urbanized area, $r_{n(0)}$ - functional radius of urbanized area, $\sigma-$ parameter of stage of town development.

To reduce a difference between land-use types and urban landscapes inside towns and urbanized zones, will use a fracture coefficient, according to (White and Engelen, 1994; Chen and Zhou, 2008):

$\lambda_{i}=\sum_{m}\left(r_{i m}-\frac{\sum_{i} d_{i m}}{D_{i m}}\right)$ 
International Journal of Mathematical, Engineering and Management Sciences

Vol. 1, No. 1, 18-25, 2016

https://dx.doi.org/10.33889/IJMEMS.2016.1.1-002

where $d_{i m}$ - size of land-use type $i$ in district or town $m, D_{i m}$ - size of urban fracture or town $m$, included different types of land-use types $d_{i m}, r_{i m}$ - distance from town $m$ to the urban centre.

$\mu_{i(x, y)}^{U R}=\sum_{n,(x, y)} \frac{r_{n}}{\lambda_{i}} A_{n} \ln A_{(x, y)} \exp \left(-\frac{r_{n}}{\left(A_{(x, y)} / \pi\right)^{1 / 2}}\right)^{\sigma}$

where $A_{n}$ - urbanized area, $A_{(x, y)}$ - square of town, $r_{n}$ - distance to urban centre, $\sigma-$ parameter of stage of town development.

Parameter of stage of urban development could be presented in a form:

$\sigma_{n(x, y)}=\sum_{n(x, y)}\left(\frac{A_{b(x, y)}+A_{i(x, y)}^{q_{m}}}{A_{(x, y)}}+\beta_{l} \frac{l_{i m}}{r_{n}}\right)$

where $A_{b(x, y)}$ is a built-up area of town, $A_{i(x, y)}$ - industrial area, $l_{i m}$ - density of roads, $\beta-$ coefficient of infrastructure availability (reflecting the road quality), $q_{m}$ - local employment rate.

So, we can conclude that vulnerability of urban population depends of distribution of urban fractures and quality urban environment: density, quality and availability of infrastructure, balance between industrial, residential and recreational zones, effectiveness of urban land use and landscape management, and social policy, particularly, employment.

Proposed equation (1) with additional components (2)-(11), which describes fatalities from natural disasters, corresponds to observed distributions. This regression is good correlating with results of other studies (Kahn, 2005).

\section{Concluding Remarks}

Modern world based on relations more than on causalities, so communicative, socio-economic, and socio-cultural issues are important to understand nature of risks and to make correct decisions. Today major part of risk analysts declared new nature of modern risks (Marti et al., 2010). We faced coherent or systemic risks, realization of which leads to domino effect (Marti et al., 2010; Kostyuchenko et al., 2012), unexpected growing of losses and fatalities (Ermoliev et al.; 2012). This type of risks originated by complicated nature of heterogeneous environment, close interconnection of engineering networks, and changing structure of society. Heterogeneous multi-agent environment generates systemic risks, which requires analyze multi-source data with sophisticated tools. Formal basis for analysis of this type of risks is developed during last 5-7 years (Ermoliev et al., 2012). But issues of social fairness, ethics, and education require further development. One aspect of analysis of social issues of risk management is studied in this paper.

On wide-scale range an education determines risk perception and so vulnerability of communities (Lutz and Samir, 2011; Kostyuchenko, 2016). But on the local level there are important heterogeneities. Land-use and urbanization structure influencing to vulnerability essentially on the temporal scale less than 3 years (regional crop rotation period) and with spatial size less than $20 \mathrm{~km}$ (size of landscape diversity). 
International Journal of Mathematical, Engineering and Management Sciences

Vol. 1, No. 1, 18-25, 2016

https://dx.doi.org/10.33889/IJMEMS.2016.1.1-002

Presented model shows that rural population distribution, and rural community's vulnerability determines by water availability, quality of soils, effectiveness of land use (including climate change adaptation), intensity of pollutions, crop productivity variations during the period of crop rotation, annual national distribution of crops output, and distance to city centres. It should noted here that "distance to city centres" is not comprehensive indicator of market accessibility in general case: quality and availability of transport infrastructure should be described more detailed on the next stages of analysis.

Urban population distribution and its vulnerability determines by distribution of urban fractures and quality urban environment: density, quality and availability of infrastructure, balance between industrial, residential and recreational zones, effectiveness of urban land use and landscape management, and social policy, particularly, employment.

It could be concluded form the model that most sustainable are networks of relatively small interlinked communities distributed in small closely located towns in rural areas, with a stable structure of land-use, provided enough water and soils of good quality, varied income distribution, and connected by accessible infrastructure. Most vulnerable are aged communities in outlying districts of degraded industrial urbanized areas, with high unemployment rate, uniformed specialized education, and low income (Kostyuchenko, 2016).

Population density is closely connected with social density, with communications and decision making. Social learning, as the function of social communications, is the way to increase sustainability.

It possible to say that social sustainability is a function of intensity and efficiency of communications between interlinked and interacted networks in the heterogeneous environment.

Therefore the results of study demonstrated that risk and security management study should include appropriate tools and approaches connected with human dimension of vulnerability (Linnerooth-Bayer et al., 2005). For instance, problems of accessibility and availability of safety resources in view of social fairness as well as socio-economic dynamics should be included into future studies in field of risk analysis. Also the social studies, population analysis should include natural resources analysis, land-use and land cover analysis issues (FAO/ADPC, 2006).

\section{References}

Albersen, P. J., Fischer, G. F., Keyzer, M. A., \& Sun, L. (2002). Estimation of Agricultural Production in the LUC-model for China. IIASA Research Report RR-02-03. Laxenburg, Austria: IIASA.

Chen, Y., \& Zhou, Y. (2008). Scaling laws and indications of self-organized criticality in urban systems. Chaos, Solitons \& Fractals, 35(1), 85-98.

Chen, Y. (2008). A wave-spectrum analysis of urban population density: entropy, fractal, and spatial localization. Discrete Dynamics in Nature and Society, 2008.

Clark, C. (1951). Urban population densities. Journal of the Royal Statistical Society. Series A (General), 114(4), 490-496.

Ermoliev, Y., Makowski, M., \& Marti, K. (2012). Robust management of heterogeneous systems under uncertainties. In Managing Safety of Heterogeneous Systems (pp. 1-16). Springer Berlin Heidelberg. 
International Journal of Mathematical, Engineering and Management Sciences

Vol. 1, No. 1, 18-25, 2016

https://dx.doi.org/10.33889/IJMEMS.2016.1.1-002

FAO/ADPC (2006). The role of local institutions in reducing vulnerability to recurrent natural disasters and in sustainable livelihoods development. Food and Agriculture Organization of the UN (FAO) and Asian Disaster preparedness Center (ADPC).

Fischer, G. (1996). Simulating the socio-economic and bio geophysical driving forces of land-use and landcover change: The IIASA land-use change model. Internat. Inst. for Applied Systems Analysis.

Fischer, G., Van Velthuizen, H., Shah, M., \& Nachtergaele, F. (2002). Global Agro Ecological Assessment for Agriculture. In in the 21st Century, Rome, Food and Agriculture Organization of the United Nations (FAO), and Laxenburg, International Institute for Applied Systems Analysis (IIASA).

Gommes, R., Das, H., Mariani, L., Challinor, A., Tychon, B., Balaghi, R., \& Dawod, M. A. (1981). Agrometeorological forecasting. Guide to Agricultural Meteorological Practices.

Kahn, M. E. (2005). The death toll from natural disasters: the role of income, geography, and institutions. Review of Economics and Statistics, 87(2), 271-284.

Kellenberg, D. K., \& Mobarak, A. M. (2008). Does rising income increase or decrease damage risk from natural disasters? Journal of Urban Economics, 63(3), 788-802.

Kostyuchenko, Y. V., Bilous, Y., Movchan, D., Márton, L., \& Kopachevsky, I. (2013). Toward methodology of satellite observation utilization for agricultural production risk assessment. IERI Procedia, 5, 21-27.

Kostyuchenko, Y. V. (2015). Geostatistics and Remote Sensing for Extremes Forecasting and Disaster Risk Multiscale Analysis. In Numerical Methods for Reliability and Safety Assessment (pp. 439-458). Springer International Publishing.

Kostyuchenko, Y. V., Movchan, D., Kopachevsky, I., \& Bilous, Y. (2015, November). Robust algorithm of multi-source data analysis for evaluation of social vulnerability in risk assessment tasks. In $S A I$ Intelligent Systems Conference (IntelliSys), 2015 (pp. 944-949). IEEE.

Kostyuchenko, Y. V. (2016). Risk Perception Based Approach to Analysis of Social Vulnerability. In Risk Perception: Theories and Approaches. Nova Science Publishers.

Kostyuchenko, Y. V., Kopachevsky, I., Zlateva, P., Stoyka, Yu., and Akymenko, P. (2012). Role of systemic risk in regional ecological long-term threats analysis. In Sustainable Civil Infrastructures Hazards, Risk, Uncertainty, 2012 (pp.551-556). Research Publishing.

Kostyuchenko, Y. V., \& Movchan, D. (2015). Quantitative parameter of risk perception: can we measure a geoethic and socio-economic component in disaster vulnerability?. Geological Society, London, Special Publications, 419(1), 79-86.

Linnerooth-Bayer, J., Mechler, R., \& Pflug, G. (2005). Refocusing disaster aid. Science, 309(5737), 10441046.

Lutz, W., \& Samir, K. C. (2011). Global human capital: Integrating education and population. Science, 333(6042), 587-592.

Marti, K., Ermoliev, Y., Makowski, M., \& Pflug, G. (2010). Coping with Uncertainty. Springer.

Movchan, D., Kostyuchenko, Y. V., Marton, L., Frayer, O., \& Kyryzyuk, S. (2014). Uncertainty analysis in crop productivity remote estimation for agricultural risks assessment. In Vulnerability, Uncertainty, and Risks Quantification, Mitigation, and Management (pp. 1008-1015). ASCE.

National report On Technogenic and Natural Security in Ukraine in 2009 (2010). Kiev: Chornobylinterinform.

Nelkin, D. (1989). Communicating technological risk: The social construction of risk perception. Annual Review of Public Health, 10(1), 95-113. 
International Journal of Mathematical, Engineering and Management Sciences

Vol. 1, No. 1, 18-25, 2016

https://dx.doi.org/10.33889/IJMEMS.2016.1.1-002

Spink, M. J. P., Menegon, V. M., Souza Bernardes, J. D., \& Coêlho, A. E. L. (2007). The language of risk in psychology: a social constructionist analysis of a psychological database. Interamerican Journal of Psychology, 41(2), 151-160.

Tian, Y., Yue, T., Zhu, L., \& Clinton, N. (2005). Modeling population density using land cover data. Ecological Modelling, 189(1), 72-88.

White, R., \& Engelen, G. (1994). Urban systems dynamics and cellular automata: fractal structures between order and chaos. Chaos, Solitons \& Fractals, 4(4), 563-583. 